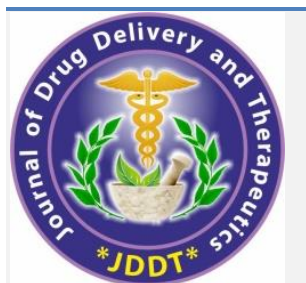

Open Access Full Text Article
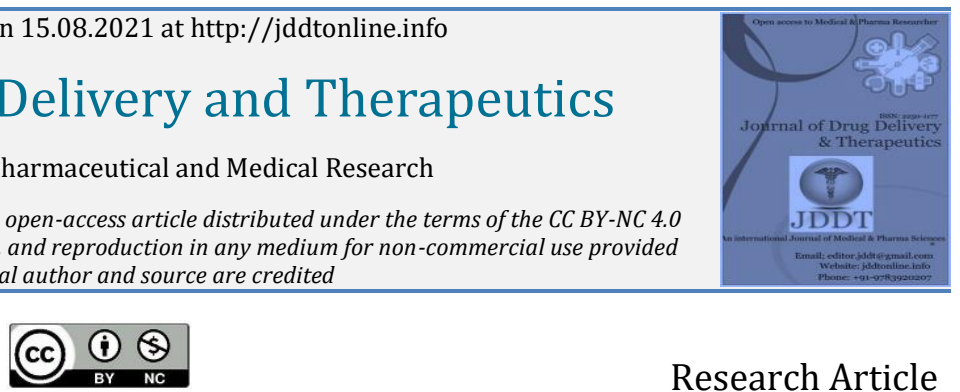

Research Article

\title{
Formulation and Evaluation of Fermented Rice Water Herbal Shampoo
}

Deduri Teja Sri*, DMunnangi Lakshmi Divya, DPotharaju Sreevani, DSuravarapu Sri Tejaswi, (D) Swami Vasavi Rama Deepthi, DUppala Vandana, DYepuri Divya, Vadlamudi Pallavi, Nadendla Rama Rao

Chalapathi Institute of Pharmaceutical Sciences, Chalapathi Nagar, Lam, Guntur, 522034, India

\section{Article Info:}

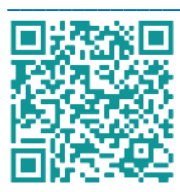

\section{Article History:}

Received 18 June 2021

Reviewed 26 July 2021

Accepted 05 August 2021

Published 15 August 2021

\section{Cite this article as:}

Meduri TS, Munnangi LD, Potharaju S, Suravarapu ST, Swami VRD, Uppala V, Yepuri D, Vadlamudi P, Nadendla RR, Formulation and Evaluation of Fermented Rice Water Herbal Shampoo, Journal of Drug Delivery and Therapeutics. 2021; 11(4S):127-130

DOI: http://dx.doi.org/10.22270/jddt.v11i4-S.4970

\section{*Address for Correspondence:}

Meduri Teja Sri, Chalapathi Institute of

Pharmaceutical Sciences, Chalapathi Nagar, Lam, Guntur, 522034, India

\section{Abstract}

Now-a-days, the most occurring problem is hair fall, so the main aim of the study is to reduce hair fall and promote hair growth. The main ingredient in this study is fermented rice water ( $\underline{\text { ryza }} \underline{\text { sativa) }}$ which contains many antioxidants when compared to the plain rice water. Inositol is the major constituent which helps in decreasing hair fall. The herbal shampoo was formulated using some of the traditional herbs like Hibiscus-rosa-sinensis, Phyllanthus emblica, Aloe vera, Trigonella foenum graceum along with fermented rice water in different concentrations and evaluated for various parameters. The prepared herbal shampoo was evaluated with physico-chemical parameters like $\mathrm{pH}$, foam formation, dirt dispersion, surface tension, viscosity and wetting test. The results states that the herbal shampoo possess the following characteristics such as good foam ability, good cleansing, low surface tension, viscosity and soothing property. The evaluation results of the herbal shampoo had shown better results, which is ideal to use, safe and effective in the treatment of hair fall.

Keywords: Herbal shampoo, Oryza sativa, Hair fall.

\section{INTRODUCTION:}

Shampoos are likely the most broadly utilized restorative items for cleaning hairs and scalp in our everyday life. In ancient times, shampoos are made up of variety of herbs and their extracts, but at present, most of the shampoos in the current market are formulated using surfactants ${ }^{1}$. The surfactants are added for their cleansing property, but it's continuous use leads to effects such as eye irritation, loss of hair and dryness of hair ${ }^{2}$. The alternative solution is to substitute the use of synthetic shampoos with the herbal shampoos.

In the present study, herbal shampoo was formulated by using the ingredients such as Hibiscus-rosasinensis, Embalica officinalis, Trigonella foenum graceum, Aloe barbadensis and fermented rice water makes hair smooth and shiny and as well as it improves the strength, texture and growth of hair. Fermented rice water contains high amount of anti-oxidants that are beneficial for hair health. Inositol, an ingredient present in the rice water has ability to penetrate into damaged hair and repairs it from the inside out. The optimal $\mathrm{pH}$ of the fermented rice water keeps hair shiny, improves skin elasticity, reduces surface friction and prevents greying of hair ${ }^{3}$.

Amla enhances the hair natural colour by preventing premature greying of hair. It has antifungal and anti-viral properties, which prevents dandruff and other fungal infections ${ }^{4}$. The seeds of Trigonella foenum graceum are rich source of iron and protein, which are two essential nutrients for hair growth. The chemical compounds such as flavonoids and saponins are responsible to induce the hair growth ${ }^{5}$.

The petals of Hibiscus rosasinensis flowers are used to stimulate thicker hair growth and to prevent hair loss and scalp disorders. Presence of amino acids and vitamin C improve the blood circulation under the scalp and boosts hair growth ${ }^{6}$. The proteolytic enzymes present in the aloe vera repairs the dead skin cells on the scalp. It acts as a great conditioner. Hibiscus rosa sinensis and Aloe barbadense help in soothing of hair and gives the hair bouncy, smooth and shiny appearance ${ }^{7}$. 


\section{MATERIALS AND METHODS:}

Table 1: Formulation table of fermented rice water shampoo

\begin{tabular}{|l|l|l|l|l|l|l|l|}
\hline S.NO & Name of the ingredient & F1 & F2 & F3 & F4 & F5 & F6 \\
\hline 1 & Rice water(ml) & 15 & 20 & 25 & 30 & 35 & 40 \\
\hline 2 & Hibiscus powder(gm) & 0.5 & 1 & 1.5 & 2 & 2.5 & 3 \\
\hline 3 & Amla powder(gm) & 0.5 & 1 & 1.6 & 2 & 2.5 & 3 \\
\hline 4 & Fenugreek powder(gm) & 0.5 & 1 & 1.5 & 2 & 2.5 & 3 \\
\hline 5 & Aloe vera gel(gm) & 0.5 & 1 & 1.5 & 2 & 2.5 & 3 \\
\hline 6 & Shampoo base & q. s & q.s & q.s & q.s & q.s & q.s \\
\hline
\end{tabular}

\subsection{Preparation of herbal shampoo:}

Taken a cup of rice in a clean bowl and rinsed with water for once to remove the dirt and impurities. Drained the water and again added some amount of water to rice and covered the bowl with heavy lid. Kept the bowl aside at room temperature for a day. Later, collected the rice water and transferred into a clean glass jar and allowed it to ferment for 2 to 3 days. To the collected fermented rice water added hibiscus powder, amla powder, aloe vera gel, fenugreek powder and stirred well until they are dispersed. Now, the solution was filtered. The filtered solution was added to the shampoo base until it attains the desired viscosity.

Table 2: Description of ingredients used

\begin{tabular}{|c|c|c|c|c|c|}
\hline S. No & Common Name & Pictures & Botanical Name & Parts used & Category \\
\hline 1. & Fermented rice water & & Oryza sativa & Seeds & Used for hair growth \\
\hline 2. & Hibiscus & & Hibiscus rosa-sinensis & Flowers & Conditioning agent \\
\hline 3. & Amla & & Phyllanthus emblica & Fruit & $\begin{array}{l}\text { Prevents pre-mature } \\
\text { greying of hair }\end{array}$ \\
\hline 4. & Fenugreek & & Trigonella foenum graceum & Seeds & Anti-dandruff agent \\
\hline 5. & Aloe vera & & Aloe vera & Leaf & Conditioning agent \\
\hline
\end{tabular}

\subsection{Evaluation parameters:}

To assess the quality of formulated shampoo, several quality control tests were performed.

\section{- Physical Appearance: 11}

The formulated shampoo was evaluated for physical characteristics such as transparency, color, odor by observing with naked eye.

\section{- pH determination:}

The $\mathrm{pH}$ of the fermented rice water shampoo was evaluated by taking $(10 \% \mathrm{v} / \mathrm{v})$ solution by using $\mathrm{pH}$ analyzer.

\section{- Test for dirt dispersion:}

Two drops of formulated shampoo were added to $10 \mathrm{ml}$ of distilled water which is taken in a wide mouthed test tube. To the test tube one drop of Indian ink was added and the test tube was shaken for $10 \mathrm{~min}$ by closing the test tube 
mouth. Volume of ink in the test tube was measured result was graded in terms of heavy, medium, none.

\section{- Foaming ability: 12}

$50 \mathrm{ml}$ of formulated shampoo taken in a test tube volume of $250 \mathrm{ml}$, shake the test tube for 10 times with time period of $1 \mathrm{~min}, 4 \mathrm{~min}$ respectively. Total foam was measured after $1 \mathrm{~min}$ of shaking. The method called as cylinder shake method.

\section{- Wetting test:}

A canvas paper weighing $0.44 \mathrm{~g}$ was cut into a disc diameter measuring 1 inch. Place it in the surface of the shampoo solution. Record the time taken by the paper to sink in the formulation and record the time by using stop watch.

\section{- Surface tension test: 13}

Formulated shampoo in clean water $(10 \% \mathrm{w} / \mathrm{v})$ was evaluated for surface tension using stalagmometer at room temperature.

It was determined by using formula:

$\mathrm{R} 2 / \mathrm{R} 1=\mathrm{w} 3-\mathrm{w} 1(\mathrm{n} 1) / \mathrm{w} 2-\mathrm{w} 1(\mathrm{n} 2)$

$\mathrm{W} 1=$ weight of empty beaker
$\mathrm{W} 2=$ weight of beaker with distilled water

W3= weight of beaker with herbal shampoo solution

$\mathrm{n} 1=$ number of drops of distilled water

n2 =number of drops of shampoo solution

$\mathrm{R} 1=$ surface tension of distilled water at room temperature

R2= surface tension of shampoo solution.

\section{- Determination of solid content: 14}

About $4 \mathrm{~g}$ of shampoo solution was placed in an evaporating dish. The liquid portion of the shampoo was evaporated by placing the dish on hotplate. Remaining solid content in the dish was calculated after complete drying.

It was determined by using the formula;

$\%$ of solid content $=\mathrm{C}-\mathrm{A} / \mathrm{B}-\mathrm{A} \times 100$

Where;

$A=$ weight of empty evaporating dish

$\mathrm{B}=$ weight of evaporating dish with shampoo solution

$\mathrm{C}=$ weight of evaporating dish after evaporation of shampoo solution.

\section{RESULTS AND DISCUSSION:}

Table 3: Physicochemical evaluation of formulated herbal shampoo

\begin{tabular}{|c|l|l|l|l|l|l|l|}
\hline \multirow{2}{*}{ S.NO } & \multirow{2}{*}{ EVALUATION PARAMETER } & \multicolumn{5}{|c|}{ OBSERVATION } \\
\cline { 3 - 8 } & & F1 & F2 & F3 & F4 & F5 & F6 \\
\hline 1 & COLOUR & Brown & Brown & Brown & Dark Brown & Dark Brown & Dark Brown \\
\hline 2 & ODOUR & \multicolumn{5}{|c|}{ CHARACTERISTIC } \\
\hline 3 & APPEARANCE & \multicolumn{5}{|c|}{ VISCOUS } \\
\hline 4 & TEXTURE & & & 7.5 & 6.8 & 6.3 & 5.2 \\
\hline 5 & pH & 8.5 & 8.2 & 7.5 & NONE \\
\hline 6 & DIRT DISPERSION & MEDIUM & MEDIUM & MEDIUM & NONE & NONE \\
\hline 7 & FOAMING INDEX (ml) & 30 & 36 & 40 & 48 & 56 & 68 \\
\hline 8 & WETTING TEST (sec) & 96 & 115 & 118 & 128 & 142 & 158 \\
\hline 9 & \% OF SOLID CONTENT & 15 & 18 & 21 & 24 & 28 & 34 \\
\hline 10 & SURFACE TENSION (dynes/cm) & 22.63 & 28.45 & 32.33 & 36.42 & 41.23 & 43.52 \\
\hline
\end{tabular}

\section{- Physical appearance:}

The formulated shampoo was assessed for visual inspection. It was observed that the formulated shampoo was clear, dark brown and possess mild odor.

\section{- $\mathbf{p H}$}

The $\mathrm{pH}$ of the shampoo plays a key role in stabilizing the scalp, improving hair quality and reducing irritation to eyes. To minimize the damage to hair, most of the shampoos are formulated either with neutral or slightly acidic $\mathrm{pH}$. The $\mathrm{pH}$ of the formulated herbal shampoo was found to be in the range of 5.2 to 8.5 .

\section{- Determination of solid content:}

In general, the good quality shampoo must possess the solid content in the range of $20 \%$ to $30 \%$, so that, it will be very easy to apply and wash out. If the solid content is more, then it is very difficult to wash out. The solid content of the formulated herbal shampoo was found to be in the range of $15 \%$ to $34 \%$.

\section{- Foaming ability and foaming stability:}

Foaming ability is one of the important parameters to be considered in the evaluation of shampoos. The foam volume of the formulated herbal shampoo was found to be in the range of $30 \mathrm{ml}$ to $68 \mathrm{ml}$. This volume had remained constant even after the observation for 4 minutes.

\section{- Dirt dispersion:}

For the evaluation of the cleansing action of shampoo, dirt dispersion test plays an immense role. Shampoos are considered of poor quality, if the ink concentrates in the foam. Based on the concentration of the ink in the foam, the results were declared as heavy, moderate, light and none. 


\section{- Wetting time:}

In order to test the efficacy of the shampoo, wetting time test is carried out. It depends upon the concentration of surfactant. The canvas disc method is preferred for calculating the wetting time. The wetting time of the formulated shampoo were found to be in the range of 96 to 158sec.

\section{- Surface tension:}

The detergency of the shampoo can be determined based on the surface tension values. Lower the value of the surface tension, more will be the cleansing action of the shampoo. The surface tension of the formulated herbal shampoo was found to be in the range of 22.63 to 43.52 dynes $/ \mathrm{cm}$.

\section{CONCLUSION:}

The main aim of formulating herbal shampoo was to reduce hair fall and promote hair growth. Herbal shampoo was formulated using traditional herbs which are very safe and effective for use. Inositol, a chemical constituent present in the rice water plays a key role in preventing hair damage, provides support to the hair strands and helpful for the hair growth. In addition to this, some herbs are used, which acts as good conditioning agents. The usage of natural conditioning agents helps in preventing hair loss compared to the use of synthetic conditioning agents. Later, the formulated herbal shampoo was evaluated for various parameters such as visual inspection, $\mathrm{pH}$, dirt dispersion, $\%$ of solid content, wetting time and surface tension. Based on the evaluation results of various formulations, it was concluded that formulation F4 has shown better results when compared to other formulations. Hence the formulated herbal shampoo was safe and effective for use and helps in reducing the hair fall.

\section{ACKNOWLEDGEMENT:}

We are grateful to Prof. Rama Rao Nadendla, Principal, Chalapathi Institute of Pharmaceutical Sciences for his continuous support and Dr. Pallavi Vadlamudi who supported and guided us for the completion of this research work.

\section{REFERENCES:}

1. R U, S D, P I. Preparation of Herbal Shampoo (HS) by Green Method and Their Characterization. Ijrssis. 2017; 5(March):2548.

2. Vijayalakshmi A, Sangeetha S, Ranjith N. Formulation and evaluation of herbal shampoo. Asian J Pharm Clin Res. 2018; 11(Special Issue 4):121-4.

3. Puram RS, Puram RS. Effective Utilization of Fermented Rice
Water. 2018; 3085(10):707-10.

4. Grover H, Deswal H, Singh Y, Bhardwaj A. Therapeutic effects of amla in medicine and dentistry: A review. J Oral Res Rev. 2015; 7(2):65. https://doi.org/10.4103/2249-4987.172498

5. Graecum F. www.wjpls.org 68 Sonu et al . formulation and evalution of two in one herbal conditioning shampoo containing extract of Allium cepa, World Journal of Pharmaceutical and Life Sciences , 2017; (August).

6. Al-Snafi AE. Chemical constituents, pharmacological effects and therapeutic importance of Hibiscus rosa-sinensis-A review Plants with antiparasitic effect View project medicinal plants with anticancer effects View project Chemical constituents, pharmacological effects. IOSR J Pharm www.iosrphr.org [Internet]. 2018; 8(7):101-19. Available from: www.iosrphr.org

7. Kumar KPS, Bhowmik D, Chiranjib, Biswajit. Aloe vera: a potential herb and its medicinal importance. Jounal Chem Pharm Res [Internet]. 2010; 2(1):21-9. Available from:

http://scholar.google.com/scholar?hl=en\&btnG=Search\&q=intit le:Aloe+vera:+A+Potential+Herb+and+its+Medicinal+Importanc e\#1

8. Bajpai SKDN. Extraction, Isolation and Evaluation of Pitera from Fermented Rice water and its Incorporation as Active in Biphasic Makeup Removal. Int J Sci Res [Internet]. 2018; 7(7):6508. Available from: https://www.ijsr.net/archive/v7i7/ART20183820.pdf

9. Article O. Potential hair growth of crude extract from Hibiscus. 2020; 11(4):13-9.

10. Wani SA, Kumar P. Fenugreek: A review on its nutraceutical properties and utilization in various food products. J Saudi Soc Agric Sci [Internet]. 2018; 17(2):97-106. Available from: http://dx.doi.org/10.1016/j.jssas.2016.01.007

11. Datta N, Pal M, Roy U, Mitra R, Pradhan A. World Journal of Pharmaceutical Research. Infection. 2014; 13(5):15.

12. Krunali T, Dhara P, Meshram DB, Mitesh P. Evaluation of Standards of Some Selected. World J Pharm Pharm Sci. 2013; 2(5):3622-30.

13. Al Badi K, Khan SA. Formulation, evaluation and comparison of the herbal shampoo with the commercial shampoos. Beni-Suef Univ J Basic Appl Sci [Internet]. 2014; 3(4):301-5. Available from: http://dx.doi.org/10.1016/j.bjbas.2014.11.005

14. Noudeh GD, Sharififar F, Khazaeli P, Mohajeri E, Jahanbakhsh J. Formulation of herbal conditioner shampoo by using extract of fenugreek seeds and evaluation of its physicochemical parameters. African J Pharm Pharmacol. 2011; 5(22):2420-7.

15. Dasaroju S, Gottumukkala KM. Review Article Current Trends in the Research of. IntJPharaSciRevRes. 2014; 24(2):150-9.

16. Lodha G. Formulation and Evaluation of Polyherbal Shampoo to Promote Hair Growth and Provide Antidandruff Action. J Drug Deliv Ther. 2019; 9(4-A):296-300. 